\title{
SUBACUTE SCLEROSING PANENCEPHALITIS PRESENTING IN A TODDLER
}

Vijayalakshmi T. N1, Basavaraj², Pushpalatha $\mathrm{K}^{3}$, Pradeep ${ }^{4}$

\section{HOW TO CITE THIS ARTICLE:}

Vijayalakshmi T. N, Basavaraj, Pushpalatha K, Pradeep. "Subacute Sclerosing Panencephalitis Presenting in a Toddler". Journal of Evolution of Medical and Dental Sciences 2014; Vol. 3, Issue 59, November 06;

Page: 13343-13346, DOI: 10.14260/jemds/2014/3778

ABSTRACT: A 2year 3 month old male toddler presented with myoclonic jerks, ataxia and progressive cognitive decline over a period of 3 months. He had history suggestive of measles at 9 months of age. A diagnosis of Sub a cute sclerosing panencephalitis was made based on clinical features, typical EEG findings and positive anti-measles IgG titre in cerebro spinal fluid. The latency period between measles infection and the onset of symptoms of subacute sclerosing pan encephalitis is commonly 6-8 years, but in this case along with some other recently published case reports suggests that there is a decreased latency period between measles infection and onset of symptoms of Subacute sclerosing panecephalitis. A differential diagnosis of SSPE should be considered in all cases of acute encephalopathy in younger age group like toddler for early diagnosis and further management.

KEYWORDS: Subacute sclerosing panencephalitis (SSPE), Toddler, Latency.

INTRODUCTION: Subacute sclerosing panencephalitis (SSPE) is a slow progressive degeneration of the central nervous system caused by a persistent defective measles virus infection. The disease has a gradual progressive course leading to death in many cases within one to three years ${ }^{1}$. The latent period between measles infection and SSPE is commonly 6-8 years ${ }^{2}$. We report a case of SSPE presenting in toddler.

CASE SUMMERY: A 2 year 3 month old male toddler born to non-consanguineous couple with normal birth and developmental history with a past history suggestive of measles at the age of 9 months presented with progressively increasing myoclonic jerks, ataxia, generalized tonic clonic convulsions and cognitive decline over a period of past 3 months. There was no history of measles in mother during antenatal period. On examination he was conscious and oriented. His vital parameters and anthropometric measurements were within normal limits.

There was no pallor, icterus or lymphadenopathy, neurocutaneous markers. On CNS examination, he had myoclonic jerks, truncal ataxia, rigidity, brisk deep tendon reflexes and extensor plantars. There was no focal neurologic deficit or cranial nerve palsy. Rest of the systemic examination was normal. Complete blood counts, ESR, serum electrolytes, liver and renal function tests were normal. His chest X ray was normal and Monteux test was negative. CSF examination showed normal cell count, protein and sugar.

An EEG was done which showed diffuse high amplitude bursts of periodic slow wave complexes suggestive of SSPE. Based on EEG picture, CSF was sent for IgG anti-measles antibodies which were positive with titre of 1:625. MRI of brain was normal. During the hospital stay his condition was progressive with increasing myoclonic jerks, generalized tonic clonic type of convulsions and gradually declining cognition was put on sodium valproate and leviteracetam. 
He developed difficulty in swallowing and his vision was gradually decreasing and had become bedridden. After knowing about the prognosis of the child parents had taken the child home against medical advice.

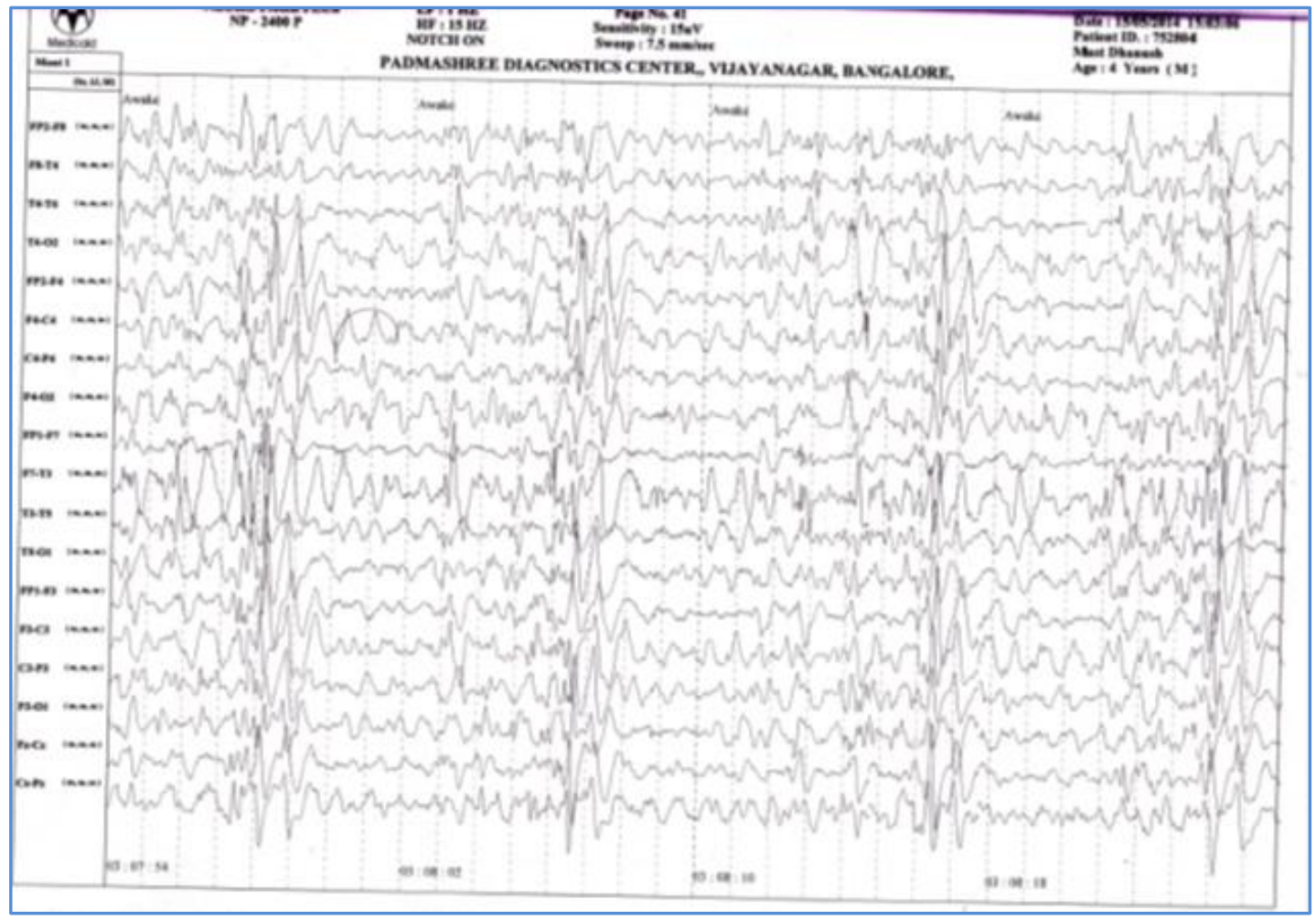

Figure 1: Electroencephalogram (EEG) at the time of presentation. EEG reveals periodic bursts of high-amplitude, slow-wave complexes. The background rhythm is normal, except for bifrontal slowing. This "burst-suppression" pattern is highly characteristic of sub-acute sclerosing panencephalitis

DISCUSSION: SSPE is a chronic complication of measles with a delayed onset and an outcome that is nearly always fatal. It appears to result from a persistent infection with an altered measles virus that is harbored intra cellularly in the central nervous system for several years. Measles at an early age favors' the development of SSPE; $50 \%$ of SSPE patients had primary measles before 2 years and $75 \%$ before 4 years of age. SSPE has been described in patients who have no history of measles infection and only exposure to the vaccine virus. However wild-type virus, not vaccine virus, has been found in brain tissue of at least some of these patients, suggesting they had subclinical measles previously. ${ }^{3}$

Clinical manifestations of SSPE begin insidiously 7-13 years after primary measles infection. Subtle changes in behavior or school performance appear, including irritability, reduced attention span. The hallmark of $2^{\text {nd }}$ stage is massive myoclonus. In the $3^{\text {rd }}$ stage, involuntary movements disappear and are replaced by chorioathetosis, immobility, dystonia and lead pipe rigidity that results from destruction of deeper Centre in basal ganglia. Sensorium deteriorates into dementia, stupor, and then coma. Stage 4 is characterized by loss of critical Centre's that support breathing, heart rate, and blood pressure. 
The diagnosis of SSPE can be established through documentation of a compatible clinical course and at least 1 of the following supportive findings (1) Measles antibody detected in CSF (2)characteristic electroencephalographic findings, or (3) typical histological findings and/or isolation of virus or viral antigen in brain tissue obtained by biopsy or postmortem examination. CSF analysis reveals normal cells but elevated IgG and IgM antibody titres in dilution of $>1: 8$. EEG is normal in stage 1 , but in the myoclonic phase Suppression burst episodes are seen that are characteristics of but not pathognomonic for SSPE.

Management of SSPE is primarily supportive and virtually all patients eventually succumb to SSPE. However, certain antiviral drugs (high dose ribavirin combined with interferon Alfa) may slow the progression of disease. This toddler presented with compatible clinical features of SSPE, characteristic EEG changes and there were elevated measles antibody titres. In this case the latency period between the onset of subacute sclerosing panencephalitis and the measles infection is very short. The literature review revealed only few case reports of SSPE in toddlers with a majority being reported to be a result of congenital measles infection. ${ }^{4-6}$

Shorter latency period between measles virus infection and onset of symptoms of SSPE in the absence of congenital 1 measles infection has been reported only recently ${ }^{6}$.The exact cause for this changing epidemiological trend remains to be ascertained. With this changing epidemiologic trend in SSPE, a high index of suspicion is needed to detect SSPE with atypical presentation like very early onset (toddler age group or may be even infancy) and shorter latency period between history of post natally acquired measles infection and symptom onset.

\section{REFERENCES:}

1. Garg RK. Subacutesclerosingpanencephalitis. Postgrad Med J. 2002; 78: 63-70.

2. Sarkar N, Gulati S, Dar L, Broor S, Kalra V. Diagnostic dilemmas in fulminant Subacutesclerosingpanencephalitis(SSPE). Indian J Pediatr. 2004; 71: 365-7.

3. Chatterjee A, Sarkar A, Mukhopadhyay J. An interesting case of SSPE without past measles and normal vaccination. Indian Journal of Medical Case Reports. 2013; 2: 30-33.

4. Dyken PR, Cunningham SC, Ward LC. Changing character of Subacutesclerosingpanencephalitis in the United States. Pediatric Neurology. 1989; 5: 339-341.

5. Simsek E, Ozturk A, Yavuz C, Kocabay K. Subacutesclerosingpanencephalitis(SSPE) associated with congenital measles infection. Turkish Journal of Pediatrics. 2005; 47: 58-62.

6. Saurabh K, Gupta R, Khare S, et al. Atypical Subacutesclerosingpanencephalitis with short onset latency. Indian Pediatrics.2013; 50: 244-245.

7. Robert M, Kliegman, Bonita F, Richerd E. Nelson textbook of Pediatrics, $19^{\text {th }}$ ed. Saunders, Philadelphia. 2011; 1072-1073. 


\section{AUTHORS:}

1. Vijayalakshmi T. N.

2. Basavaraj

3. Pushpalatha K.

4. Pradeep

\section{PARTICULARS OF CONTRIBUTORS:}

1. $2^{\text {nd }}$ Year Post Graduate, Department of Paediatrics, ESIC, MC PGIMSR.

2. Assistant Professor, Department of Paediatrics, ESIC, MC PGIMSR.

3. HOD \& Professor, Department of Paediatrics, ESIC, MC PGIMSR.

4. Senior Resident, Department of Paediatrics, ESIC, MC PGIMSR.

\section{NAME ADDRESS EMAIL ID OF THE CORRESPONDING AUTHOR:}

Dr. Vijayalakshmi T. N, $2^{\text {nd }}$ Year Post Graduate, Department of Paediatrics, Room 4, $1^{\text {st }}$ Floor,

PG Ladies Hostel, ESIC MC PGIMSR,

Rajaji Nagar,

Bangalore-10.

Email: vijayalakshmi35@yahoo.com

Date of Submission: 21/10/2014. Date of Peer Review: 22/10/2014. Date of Acceptance: 04/11/2014. Date of Publishing: 06/11/2014. 